\title{
DEVELOPMENT OF DISPLACEMENT GAGES EXPOSED TO SOLID ROCKET MOTOR INTERNAL ENVIRONMENTS
}

\author{
D. E. Bolton, D. J. Cook \\ ATK Thiokol Propulsion, Brigham City, Utah
}

\begin{abstract}
The Space Shuttle Reusable Solid Rocket Motor (RSRM) has three non-vented segment-to-segment case field joints. These joints use an interference fit J-joint that is bonded at assembly with a Pressure Sensitive Adhesive (PSA) inboard of redundant O-ring seals. Full-scale motor and sub-scale test article experience has shown that the ability to preclude gas leakage past the J-joint is a function of PSA type, joint moisture from pre-assembly humidity exposure, and the magnitude of joint displacement during motor operation. To more accurately determine the axial displacements at the J-joints, two thermally durable displacement gages (one mechanical and one electrical) were designed and developed. The mechanical displacement gage concept was generated first as a nonelectrical, self-contained gage to capture the maximum magnitude of the J-joint motion. When it became feasible, the electrical displacement gage concept was generated second as a real-time linear displacement gage. Both of these gages were refined in development testing that included hot internal solid rocket motor environments and simulated vibration environments. As a result of this gage development effort, joint motions have been measured in static fired RSRM Jjoints where intentional venting was produced (Flight Support Motor \#8, FSM-8) and nominal non-vented behavior occurred (FSM-9 and FSM-10). This data gives new insight into the nominal characteristics of the three case J-joint positions (forward, center and aft) and characteristics of some case J-joints that became vented during motor operation. The data supports previous structural model predictions. These gages will also be useful in evaluating J-joint motion differences in a fivesegment Space Shuttle solid rocket motor.
\end{abstract}

\section{INTRODUCTION AND BACKGROUND}

This paper presents the design and development of displacement gages used to measure motions in the field joint insulation of the Space Shuttle Reusable Solid
Rocket Motor (RSRM). To better cover this topic, some basic background information is in order. The RSRM is composed of four segments that are assembled to make a full-length motor (see Figure 1). The interfaces between the four segments make three "field joints". Each field joint is composed of a "tang" and "clevis" which are the mated parts of the steel case ends. Each case joint has a redundant seal system made up of two O-rings. Inboard of the sealing O-rings there is a steel interference fit, a "capture feature" O-ring and an internal insulation "J-joint". These inner joint features are thermal barriers which protect the O-ring seals.

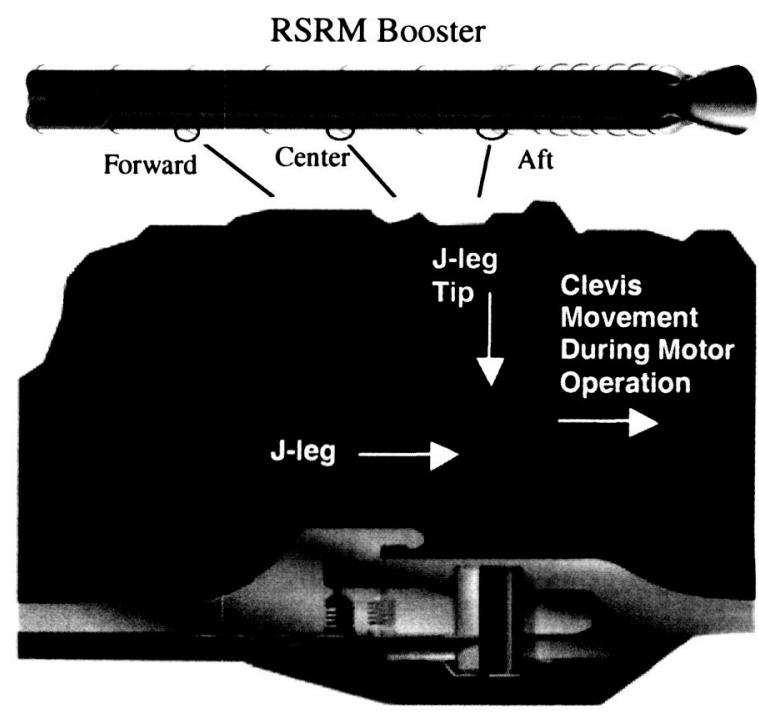

Figure 1. Assembled RSRM Internal Insulation Field Joint (J-Joint) Configuration

A Pressure Sensitive Adhesive (PSA) is used on the mating surfaces of the $\mathrm{J}$-joint insulation. A change to the PSA on the STS-78 (RSRM-55) flight motors resulted in significant gas intrusion into four of the six $\mathrm{J}$-joints (center and aft J-joints of both motors). As a

Copyright @ 2003 by ATK Thiokol Propulsion, A Division of ATK Aerospace Company,

Published by the American Institute of Aeronautics and Astronautics, Inc.

with permission. 
result of this occurrence, an investigation of the J-joint gas intrusion was performed. A more detailed discussion of this investigation is presented in Reference 1. Based on the findings of RSRM-55, subsequent static test motors and J-joint analog tests, joint motion was identified as a key variable in the performance of the J-joint. Based on structural analysis, the center field joint was predicted to have the most motion at ignition, followed by the aft field joint and then the forward field joint. Unfortunately there was moderate uncertainty as to the magnitude of the Jjoint analysis displacements. J-joint motion had never been measured.

The primary J-joint motion is an axial displacement of the clevis side insulation that occurs in the first few seconds of motor operation. The J-joint motion is the result of propellant grain deformations. The primary drivers for this motion are case deflection as a function of pressure, and differential pressure drop down the bore of the motor.

The need to better understand the J-joint motion was the driving force in the gage development efforts discussed in this paper. The main objective was to measure the maximum displacement that occurs near the start of motor operation. Gaining time dependent displacement data was of secondary importance.

\section{MEaSuREMEnT ChaLlenges}

There were a number of challenges associated with obtaining J-joint motion measurements. The most important requirement was that the measurement could not adversely impact the performance of the J-joint or the motor. Concerns associated with potential motor impacts included: risk of accidental propellant ignition, risk to structural integrity, risk to thermal performance adequacy, risk of changing $\mathrm{J}$-joint functionality and potential for generating debris impacts in the motor.

A second set of challenges was associated with the functionality of the measurement devices. These included: survival of the measurement device in the extremely hot and non-clean solid rocket motor environment (combustion gases, soot and slag) and retrieval of the measurement (either external to the motor or inside the motor after the test).

A brief summary of how these challenges were addressed is described in this paper.

\section{INITIAL DISPLACEMENT GAGE CONCEPTS}

A key feature contributing to the success of this endeavor was identifying an acceptable location for the measurement gages. Figure 2 shows a schematic of an electrical displacement gage positioned behind the "J-leg" of a J-joint. This region of the J-joint has very low strains before, during and after motor operation. This region is also much thicker than required for thermal protection of the case. As a result, the main body of the gages can be placed outboard of the expected thermal degradation. By maintaining the gages in a region of un-degraded insulation, the risk associated with a debris concern inside the motor was mitigated. The gages remain bonded in and mechanically confined by the un-degraded insulation. Subsequent thermal analysis showed that there was no unacceptable heating of the insulation surrounding the gages as a result of their placement.

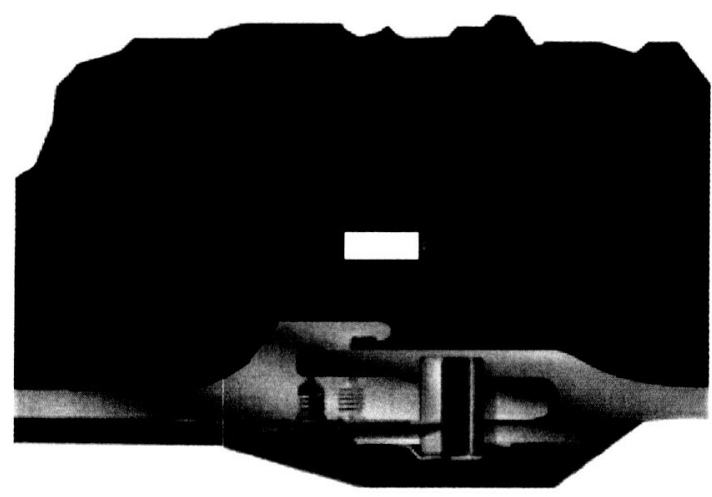

Figure 2. Displacement Gage Placement in the J-joint

By being behind the J-leg, and making contact with an extremely low force, the gage did not impact the typical functionality of the J-joint. Any potential disturbance would be to assist the contact between the two sides of the J-joint.

\section{MECHANICAL DISPLACEMENT GAGE CONCEPT}

The mechanical displacement gage was the first gage concept developed. A significant constraint at that time was an absence of any electrical wires going through the RSRM case. This constrained the possibilities to self-contained measurement concepts that could store the data, or transmit the data for external storage. Considering complexity, reliability, development requirements, and safety issues (batteries located near solid rocket motor propellant), the decision was made to pursue a simple mechanical displacement gage. 
Based on an analysis of the expected environmental loads, the maximum J-joint motion was expected just after the initial pressurization of the motor. As a result, a displacement gage could measure the maximum displacement if it only remained functional for a relatively short time (a few seconds). This maximum displacement could then be used to anchor the corresponding J-joint structural analysis. Capturing the maximum displacement is a relatively simple measurement.

The initial design of the mechanical displacement gage included a spring loaded actuation rod which pushed slides to the extremes of the rod travel (see Figure 3). The back slide would be set during installation to correspond with the back of the "pressurization slot" (the gap between the J-leg and the insulation which holds the body of the gage). The front slide would be pushed forward during motor operation to the maximum opening of the pressurization slot. The opening during motor operation could be determined from a comparison of the maximum opening and the predicted pressurization slot gap at assembly. This assembly gap is standardly determined from pre-assembly joint measurements.

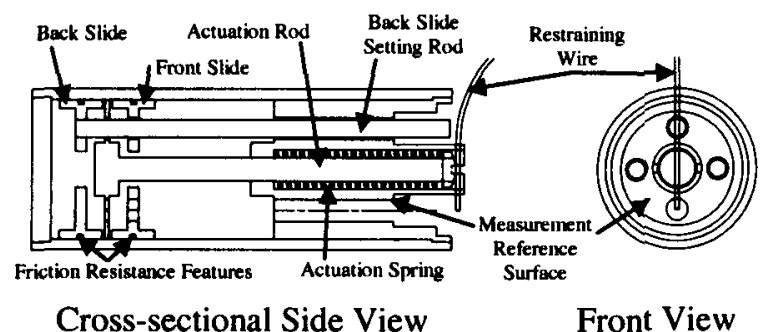

\section{Figure 3. Overall Mechanical Displacement Gage Configuration}

Another feature of the mechanical displacement gage is a low melting temperature $\left(360^{\circ} \mathrm{F}\right)$ solder washer on the front end of the actuation rod that holds the spring in place. The purpose of this solder is to allow the natural hot environment to release the spring after the maximum displacement occurs early in motor operation. Then when the J-leg is extended during motor disassembly, the actuation rod would not push the front slide past the operational measurement position.

This actuation rod arrangement would only work if it was constrained until after joint assembly. To facilitate this initial rod constraint, a restraining wire was used in front of the rod. This required that the retaining wire be removed by an operator inside the motor after each joint assembly. Fortunately, the size of the RSRM makes this possible. This type of motor bore entry was not a new process.
To ensure that the position slides would not move due to vibration, pressurization or other potential loads, friction resistance features (somewhat like rings on an automotive engine piston) were put around the outside of each position slide. The friction of the slides directly affected the required strength of the actuation spring. There was concern that this friction may change as a result of humidity and aging in the motor prior to the actual motor firing. To mitigate this concern, and to obtain a relatively high thermal durability of the gage components, all the parts of the mechanical displacement gage (except for the solder washer at the tip) were fabricated from stainless steel.

The actuator rod spring was tailored to be capable of overcoming the slider friction and push through some soot and slag particle buildup that could enter the gage during motor pressurization.

To enable reading of the measurement slides within the gage, several holes were drilled from the front of the gage through the various components. To read the measurement slide positions, a rod was extended into the appropriate hole to the point that it contacted the desired slide. These rod depths were then used to calculate the extents of the actuator rod travel. Analysis showed that these measurement reading holes also allowed the gage to pressurize with motor gases without enough pressure drop to move the measurement slides.

The front of the mechanical displacement gage was predominately solid with the noted measurementreading/gage-venting holes. The front end acted as a heat sink to reduce the temperatures of the pressurizing gases before they reached the smaller parts further back in the gage.

The mechanical gage design has a reference surface $\sim 1 / 4$ " behind the front portion of the gage that mounts flush with the pressurization slot surface. This allows the gage measurements to be taken post-test if up to $1 / 4$ " of the gage were to melt off during RSRM motor operation.

The gage had one slide setting rod which extended from the back measurement slide to the front of the gage. This enabled the back slide to be "reset" from the front of the gage. This rod also helps maintain alignment of the measurement holes.

\section{ELECTRICAL DISPLACEMENT GAGE CONCEPT}

The electrical displacement gage was the second gage concept developed. This second gage was made 
possible by an independent development effort that created a method for getting instrumentation wires through the RSRM case ${ }^{2}$. With this new opportunity available, a concept was generated that would thermally toughen an existing technology-based linear displacement gage to function inside of the RSRM motor environment. There were a number of potential benefits with an electrical displacement gage. This gage could measure the displacement as a function of time and not just the maximum displacement. This gage would permit data collection outside the motor so that post-test disassembly measurements were not required. There was no retaining wire that required removal from inside the motor.

There were a few new concerns with the electrical displacement gage beyond those of the mechanical displacement gage associated with their electrical nature. These were electrical failure and gage heating scenarios that had to be addressed. A method of connecting to instrumentation wires imbedded in the internal insulation had to be developed.

The initial design of the electrical displacement gage utilized a linear displacement gage that was relatively low cost and had been used in a number of cold pressurized tests with good success (see Figure 4).

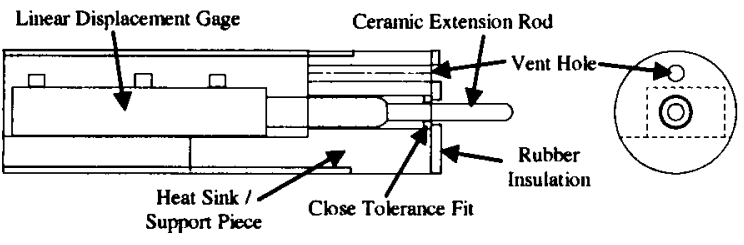

Cross-sectional Side View

Front View

Figure 4. Overall Electrical Displacement Gage Configuration

A ceramic extension rod was added to the end of the standard actuation rod to increase the potential survival time of the gage. This ceramic tip was made from a commercially available sheath commonly used to protect thermocouples in high temperature environments. The ceramic tip was both bonded with high temperature adhesive and crimped in place with a brass attachment sleeve.

A stainless steel gage front and support piece acted as a heat sink to cool gases pressurizing the gage. The gage front had a vent hole away from the measurement tip to minimize the gas that pressurized the gage along the actuation shaft. The front of the hole for the ceramic measurement tip was a close tolerance fit with the ceramic actuation shaft to further reduce the gas that pressurized the gage along the actuation shaft. The back of the same hole was counter bored to a larger diameter to provide better soot and slag tolerance (motion of the ceramic actuator shaft without binding).

An epoxy was used to back-fill most of the free volume in the back portion of the gage. This minimized the quantity of hot gas that was needed to pressurize the gage.

A thin layer of case insulation rubber was bonded to the front of the gage to reduce the post pressurization heating of the gage front. The holes in this front insulation were sized to preclude contacting the ceramic tip and restriction of the vent hole.

\section{DETERMINATION OF DEVELOPMENT / VERIFICATION EFFORT}

After the initial concept for the gages was generated, an overall development and verification plan for using the gages was generated. Figure 5 shows a summary of the verification flow. By generating this outline, key testing and evaluations were identified for team review and buy-in. This ensured that important items of concern would be addressed in a logical and timely manner that would meet the required time lines of the RSRM static test motor that would first use the gages. An overview of this development/verification effort is presented here.

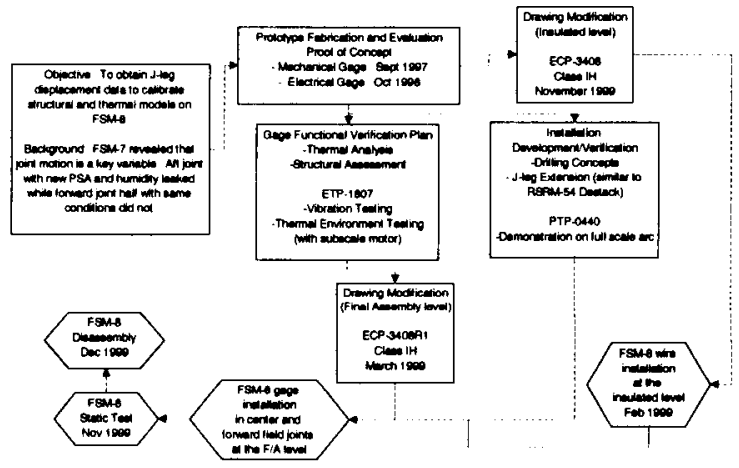

Figure 5. Displacement Gage Development and Verification Flow

In considering the pros and cons of the two displacement gage types, it was decided that both would be carried through the development and verification process. Then, if either gage was found to be deficient, the other gage would still provide an opportunity to obtain the key motion data. Also, if both gages were found acceptable, the mechanical displacement gages would provide backup for the electrical displacement gages. 


\section{GaGe InSTALlation Process DeVELOPMENT}

The development of acceptable installation processes that would be reliable and have no adverse motor impacts or safety risks was essential. For this reason, installation issues were part of the previously mentioned gage development and verification plan. Some of the key installation features and logic are presented in this section.

The first key installation decision was to drill and install the gages after case insulation cure, as opposed to curing the gages in place. The primary driver for this was the need for very accurate positioning of the gages. Some other instrumentation like thermocouples (TCs) and eroding potentiometers (EPs) are layed up and cured with the case insulation. For TCs and EPs, small amounts of position shift due to insulation material flow during cure are not detrimental to their measurement accuracy. The possibility of modifying key fabrication tooling to hold the displacement gages during insulation cure was cost prohibitive. Another reason for installing the gages after insulation cure was to avoid putting the electrical displacement gages through the elevated temperature cycle for the cure $\left(-300^{\circ} \mathrm{F}\right.$ for a number of hours).

A modification to the desired installation time was required to get the gages on the desired test motor (FSM-8). Because of the significant fabrication time and gage development/verification effort, the gages would not be ready until the motor segments were at the loaded level (filled with solid rocket motor propellant). This increased the complexity of the installation process because of the safety issues associated with working near live solid propellant. However, there were no significant issues with the electrical lead wires, so they were implemented with the insulation layup process. This staggered implementation is noted in Figure 5. The possibility that the wires would be installed and not used was deemed an acceptable scenario.

For motors after FSM-8, the drilling process was performed prior to loading (casting and curing) the segment with propellant. For these motors, solid cylinders were temporarily placed into the holes to help hold the size and shape of the drilled hole through the remaining processing prior to gage installation.

To connect the embedded wires to the electrical displacement gage, a tapered Teflon plug was formed in the insulation with several wraps of the lead wires around its outer diameter. To reduce the risk of losing a gage because of a lead wire loss, four wires were typically routed for each 3-wire gage. The Teflon plug was positioned adjacent to the desired electrical displacement gage position. After insulation cure, the Teflon plug was removed and the gage hole drilled. After wire connection, the surface was repaired with the standard repair epoxy.

A number of processing tools were devised to facilitate the gage hole drilling operation. Two J-leg extending tools (Figure 6) were used to pull the J-leg toward the case tang where aluminum brackets were used to hold the $\mathrm{J}$-leg in an extended position (Figure 7). A drill guide (Figure 8) was then clamped to the case tang between two aluminum brackets. To avoid the risk of scratching the case tang (steel), all potential contact surfaces were made of aluminum.

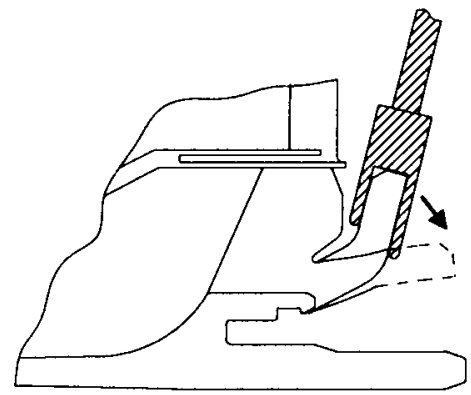

Figure 6. J-leg Extending Tool (Cross-section View)

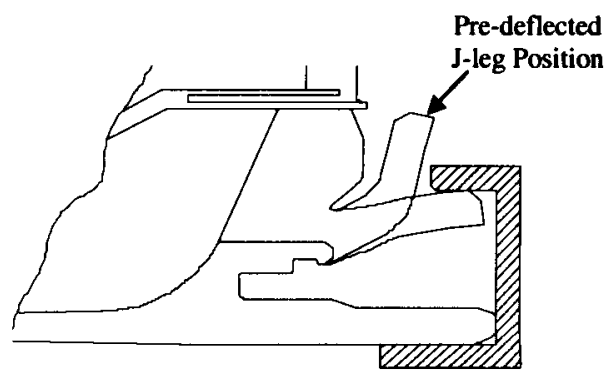

Figure 7. J-leg Holding Bracket in Extended Position (Cross-section View)

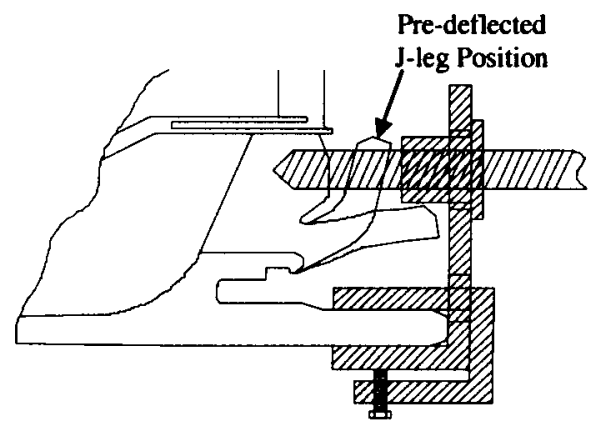

Figure 8. Schematic of Drill Guide Attached to Metal Tang (Cross-section View) 
These processing tools were checked out and the process developed on full-scale insulated hardware that was scheduled for refurbishment. Various drill bit sizes and honing times were evaluated to identify the best fit for the $3 / 4$ " diameter displacement gages. A larger drill bit than the hole was required with additional honing time because the insulation partially stretches outward from the drill bit during drilling.

Temperature monitoring of the drill bit was important due safety concerns associated with the proximity to live solid propellant. Therefore, during the process development drilling, bit temperatures were monitored for various durations of honing in the gage hole. Based on this temperature data and a conservative thermal analysis, a maximum honing time and drill bit temperature were established. During actual gage hole drilling on motor hardware, the drill bit temperature was measured after each honing time to ensure that the temperatures remained within the established limits. The drill bit was then cooled with a de-ionized water dampened cloth below a given level before honing could resume. This successive short duration honing continued until an adequate fit was determined with a witness tube of the same diameter as the gages (3/4").

There were several additional safety precautions to ensure safe drilling near the live propellant. A pneumatic drill was used and inspected often. A safety sleeve was used on the drill bit to ensure that an excessively deep hole could not occur if the adjustment sleeve were to come loose. Set screws were regularly checked for tightness during the drilling process. A static dissipative plastic cover was used over the propellant during drilling operations. Electrostatic Energy (ESE) buildup measurements verified surface voltages well below safe standards. A grounded vacuum with a grounded hose end was used to suck up all insulation shavings.

In conjunction with the full-scale process trials, J-leg position recovery measurements were made to ensure that the J-leg deflection process did not adversely affect the J-leg configuration. This testing showed that the Jleg would return to almost its initial position within 24 hours. The recovery process continues for longer than that time, but the data taken for 24 hours showed adequate return. The small amount of position difference that may remain, would actually increase the axial engagement which is viewed as generally beneficial to the J-joint. Assembly of the J-joint brings the J-leg into the same final baseline position.

Gage bonding into the drilled hole was practiced during the process development testing. Adhesive was applied to the gage body and the gage hole. A wire was put along the inside of the hole prior to inserting the gage. The wire helped facilitate air escape from behind the gage. Without the wire, the compressed air behind the gage that would push the gage back out of the hole. After the gage was properly positioned in the hole, and the air behind it released, the wire was pulled out from alongside of the gage.

\section{GAGE DEVELOPMENT/REFINEMENT AND VERIFICATION TESTING}

There were two key areas for gage development and verification testing. These areas included vibration testing associated with an RSRM static motor test, and hot gas pressurization / operation associated with a solid rocket motor environment

Both displacement gages were vibration tested on inhouse vibration equipment (shaker table) at levels previously defined by NASA documentation for acceptance testing for the RSRM environment. For both mechanical and electrical gages, there were no signs of any physical changes as a result of the vibration testing. The electrical gage did not shift or drift but remained constant with an extremely low (acceptable) level of noise (equivalent to a range of $\sim 0.0005$ ").

Both gage types were tested in small char motors for a rough simulation of the first 10 seconds of the RSRM static motor environment. Although it was desirable for the electrical gage to survive for the full duration (roughly 120 seconds), the data would still have been considered successful if the gage only survived for several seconds.

A modified configuration JIETA (Jet Impingement and Erosion Test Article) motor was used to test the gages. Figure 9 shows a cross-section of the basic JIETA Motor. Some key features of this motor include: two chambers, "T" shaped inner chamber (3.0" metal case inner diameter), an end burning grain of tailorable length to control burn time ( 10 second experience maximum), an inner orifice of tailorable size to direct/accelerate propellant gas flow onto a test specimen, a tailorable exit nozzle to control the motor pressure (typical 0.14" diameter for RSRM simulations), igniter and pressure ports, and insulation thick enough for multiple motor tests. 


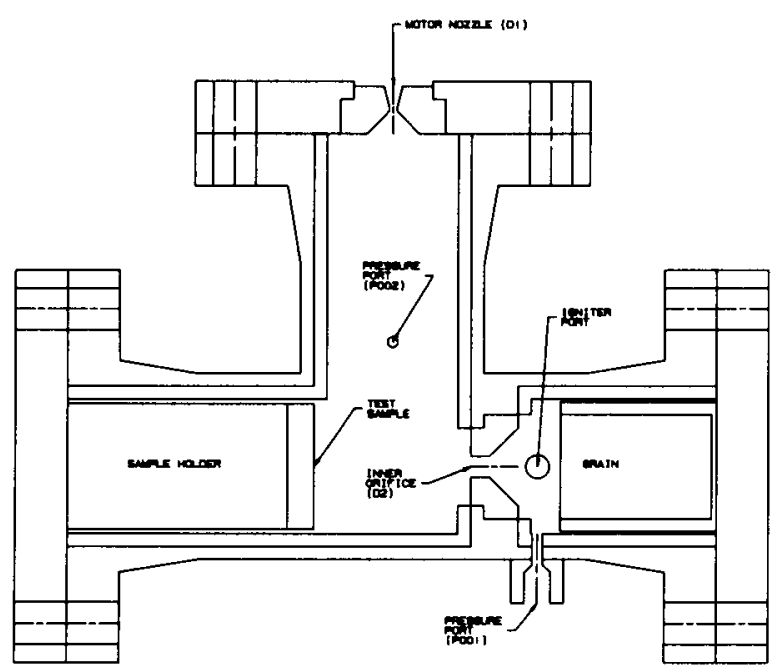

Figure 9. Basic JIETA Motor Configuration (Cross-section View)

For the displacement gage tests, the typical JIETA motor test specimen and specimen holder were replaced with a special gage holder/testing sub-assembly (see Figure 10). Some key features of this sub-assembly included: insulation surrounding the sides and back of the gage thick enough to prevent any heating from those directions, a gap for motor gases to reach the gage similar in size to that expected in the RSRM, a sealed empty cavity in front of the gage which would be compressed as the motor pressurized, and an instrumentation wire pass-though port in the end plate behind the gage for the electrical displacement gage. This sub-assembly allowed the gage to measure a surface moving away from the gage as the gage was pressurized.

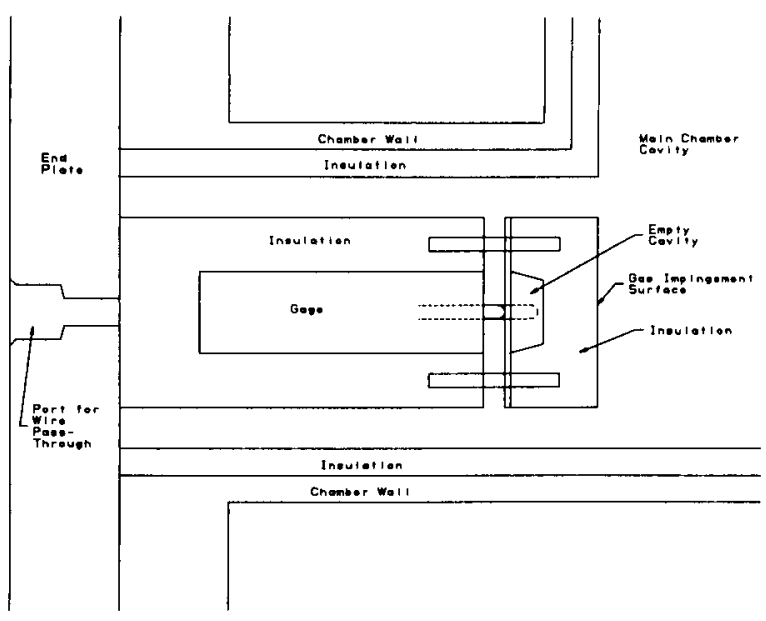

Figure 10. JIETA Motor Sub-assembly for Displacement Gage Testing (Cross-section View)
One JIETA motor was fired with each displacement gage type. The motors performed as expected. Displacement data was collected from the electrical gage during motor operation. (This data will be discussed in subsequent paragraphs.) Both gages were carefully removed from their test sub-assembly, disassembled and evaluated.

There were some key findings for the first mechanical displacement gage. Most were acceptable including: 1) The solder had melted from the extension probe tip. 2) The extension probe was stuck in place and would not move outward with moderate force. 3) There was motor soot residue holding the actuation rod in place. The soot tended to prevent the slides from moving. 4) There were no indications of adverse heat effects to the gage. The only finding that was undesirable was that the actuation spring was still stuck to the extension probe.

There were some key findings for the first electrical displacement gage. Most were acceptable including: 1) Soot deposits were found inside of the case body as expected. 2) The data from Figure 11 showed no sticking in the first second of motor operation. 3) The maximum motion measured was 0.251 ". 4) There were no signs of any thermal decomposition or degradation of the plastic parts of the linear potentiometer or any other gage parts. This indicated that the plastic parts did not exceed $\sim 435^{\circ} \mathrm{F}$. The one finding that was undesirable was that the ceramic tip would stick in position when it was pushed in approximately $1 / 4$ " as a result of soot buildup. Soot was considered a potential contributor to the rapid shifts at roughly 2.1 and 5.2 seconds. At that time the specific shifts in the data were not understood.

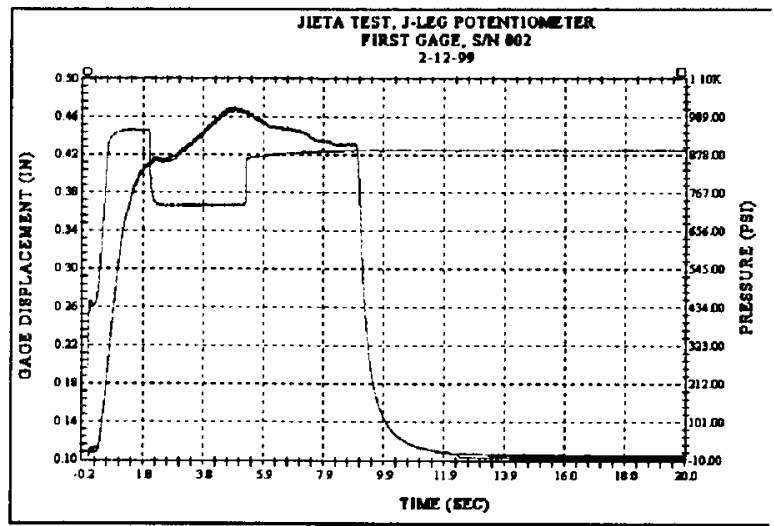

Figure 11. Data from First Electrical Displacement Gage JIETA Motor 
These first post-test observations/findings showed some gage conditions associated with the sooty motor environment that were less than desirable. Minor modifications were identified that would most likely improve the performance of the gages by improving the gage mechanisms' ability to move in a sooty environment.

For the mechanical displacement gage, one small modification was made. To reduce the tendency of the spring to bind against the extension probe, the rod diameter and associated guide hole were reduced by 0.021 ". This significantly increased the spring clearance without changing the allowed motion of the extension probe. It was also determined that this minor change would not adversely impact the vibration characteristics of the mechanical gage. If anything, the slight reduction in extension probe mass would make it less susceptible to vibration effects. As a result, the vibration tests were not repeated.

For the electrical displacement gage, two small modifications were made. First, the length of the ceramic tip contact region at the front of the guide hole was reduced from 0.15 " to 0.05 ". This reduced the area for potential soot binding. Given the same spring, the effective shear in the contact region would be much higher before the binding would occur. As a result, the spring should be able to push against greater soot buildup. As a result of this modification, the gage was shifted forward by 0.10 " and the internal volume inside the gage (after epoxy backfill) was reduced. Second, the vent hole in the front of the gage was increased from 0.086 " to 0.125 ". This doubling of the vent hole flow area reduced the amount of gas that pressurized the gage along the extension probe.

It was determined that neither of these minor changes would affect the vibration characteristics of the electrical displacement gages. As a result, the vibration tests were not repeated.

A second JIETA motor test was run for each type of gage. Like the first set of motors, the gages were disassembled and evaluated after the tests. Some of the key finding differences for the second mechanical displacement gage JIETA test included the following: 1) The portion of the spring in view on the extension probe was compressed with most of the spring loops at the tip end. 2) The temper in the spring was gone due to the motor heating. 3) The extension probe and internal sliders were stuck more firmly in place than in the first mechanical displacement gage motor test. 4) A comparison of calculated motions showed good correlation to those of the electrical displacement gages.
All of these findings were deemed acceptable and indicated that the gage functioned as expected early in motor operation.

All of the key findings for the second electrical displacement gage JIETA test were deemed acceptable including the following: 1) The ceramic tip did not stick and moved similar to the pre-test condition. 2) There appeared to be less soot on the actuator shaft in the electrical contact area. 3) There were no indications of any adverse heating effects. 4) The gage response (including the shifts in the data) was very similar to in the first JIETA motor test (see Figure 12 and compare with Figure 11). 5) The maximum motion measured was 0.268 ". (To determine the maximum J-leg tip displacement, pre-ignition value must be subtracted from the maximum value.)

A reasonable scenario was generated for the shifts in the data. As a result, it did not appear that sticking occurred during motor operation. A brief summary of this scenario includes (refer to Figure 10): 1) a collapse of the thin insulation into the empty cavity in front of the gage at ignition, 2) motor gas leakage into the cavity through a weakened epoxy bond (@ 1.7 to 2.0 seconds), 3 ) the ceramic probe tip pushed through the thin heat affected insulation(@5.3 to 5.6 seconds),4) Minor motion during the remainder of the motor due to continued thermal degradation of the insulation in front of the gage. These shifts are an artifact of the subscale test fixture and would not occur in the full-scale application. They do indicate that the gages continued to track motions during the subscale test.

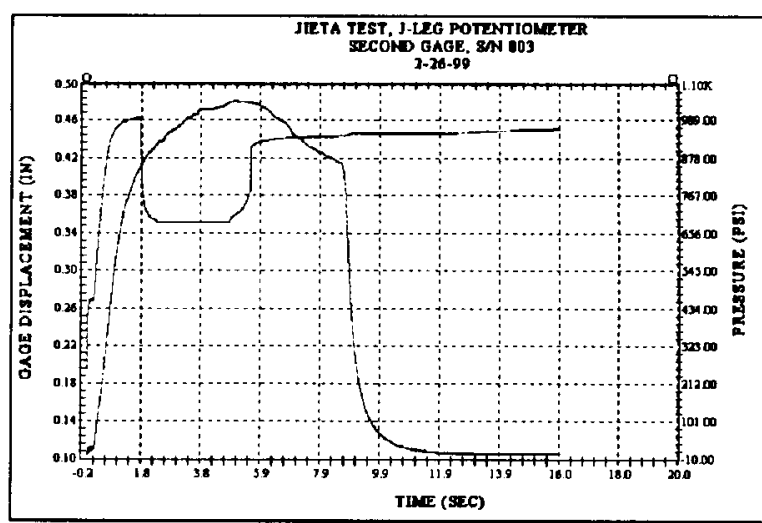

Figure 12. Data from Second Electrical Displacement Gage JIETA Motor

A supplemental check was run to verify the accuracy of the linear displacement gage. The linear potentiometer component of the gage is inherently temperature insensitive. The manufacturer specification indicates a 
standard operating range of -40 to $275^{\circ} \mathrm{F}$. Testing showed no shift in the gage response up through $350^{\circ} \mathrm{F}$. Between 350 and $390^{\circ} \mathrm{F}$ the maximum error was within $1 \%$ of the motion range ( 0.550 "). Between 390 and $430^{\circ} \mathrm{F}$ the maximum error was within $2 \%$ of the motion range. The linear potentiometer component deformed and came apart at about $435^{\circ} \mathrm{F}$. This accuracy was acceptable for the J-joint displacement measurements.

With acceptable behavior from both displacement gage types, no additional changes were made and the gage implementation was continued on FSM-8.

\section{FULL SCALE MOTOR IMPLEMENTATION AND RESULTS}

\section{FSM-8}

With the acceptable completion and results of the development and verification efforts, mechanical and electrical displacement gages were implemented on the forward and center field joints of FSM-8. The aft field joint had separate objectives that precluded gage use on that joint. Figure 13 shows the circumferential gage layout for each of the field joints.

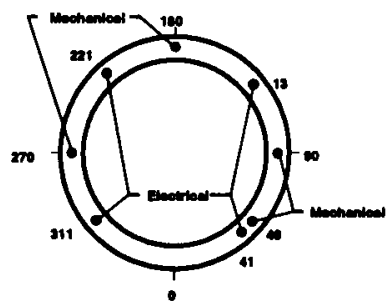

\section{Figure 13. Circumferential Orientation of} Displacement Gages (Aft looking Forward)

FSM-8 was the first motor to implement the internal instrumentation wires inside an RSRM motor.

Unfortunately, with a new configuration and some tough luck, there were a significant number of instrumentation wires that lost continuity. Some of these were lost before and some after gage installation. There were several locations that had lost two of the four lead wires prior to gage installation. This meant that the gages could not function as planned. As a last attempt effort to obtain data at these locations, the gages were converted into 2-wire resistance gages which were calibrated in place. The accuracy of this approach was unknown, but there were no limiting safety issues. The biggest concern was that the 2-wire resistance gage could have much more temperature sensitivity than the 3-wire potentiometer.
Electrical displacement gage data was obtained for one standard 3-wire gage in the forward field joint and two re-configured 2-wire resistance gages in the center field joint. The standard gage performed very well and appeared to capture an intentionally created J-joint gas intrusion event between roughly 10 and 25 seconds (see Figure 14.) Confidence that this was correct increased when comparison data from the nominal FSM-9 forward field joint was obtained. The maximum displacement just after ignition was 0.185 " that was not much below the 0.21 " analytical prediction. Data from the re-configured 2-wire gages on the center field joint were not well behaved, became more unbelievable over time, and contained much more noise. Figure 15 shows the better of the two 2-wire resistance gages. This gage also appears to capture the start of an intentionally created J-joint gas intrusion at roughly 1.5 seconds. The only consistent feature of the center field joint 2 wire resistance gages was that both indicated a 0.320 " displacement near motor ignition that was close to the 0.30 " analytical prediction.

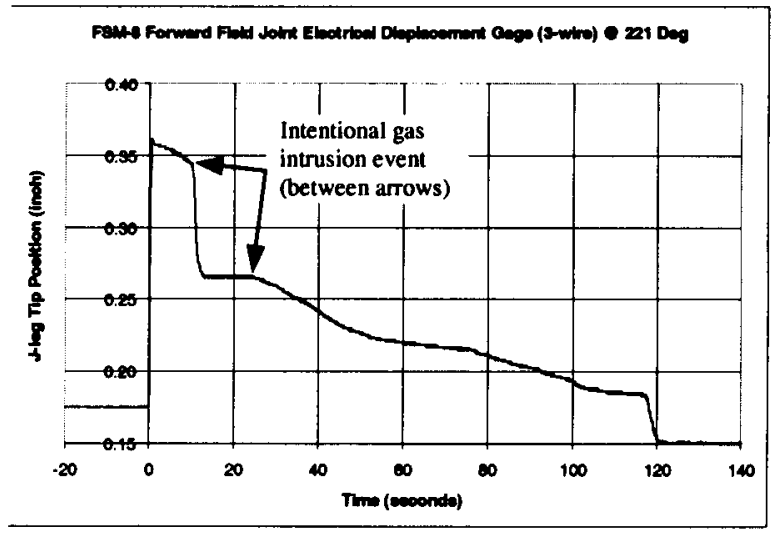

Figure 14. FSM-8 Forward Field Joint Electrical Displacement Gage Data

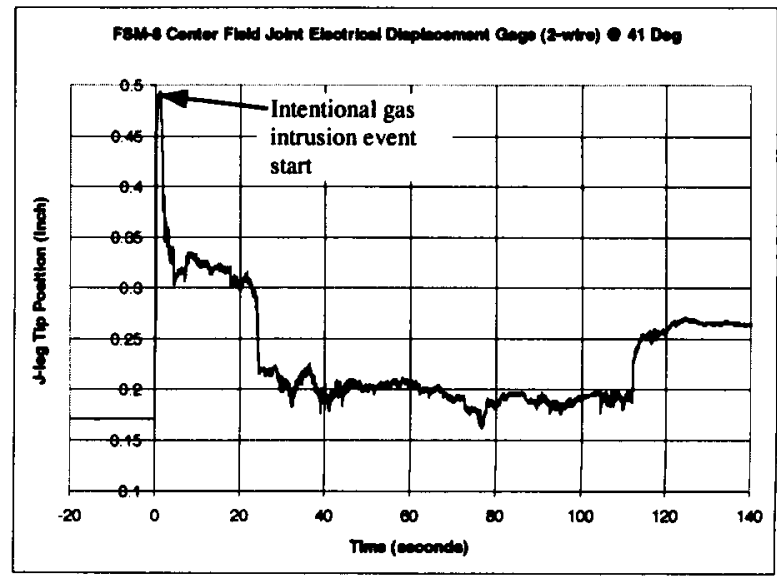

Figure 15. FSM-8 Center Field Joint 2-wire Re-configured Electrical Displacement Gage Data 
The mechanical displacement gage results on FSM-8 were even more disappointing. Although the gages survived the motor firing in good condition, the data was consistently and unrealistically low. The reason for this was never fully understood. A minor change was made to subsequent mechanical displacement gages to extend the body length by 0.10 " to ensure adequate room for the back slide to move. This did not affect any moving parts of the gage.

\section{FSM-9}

With experience gained from the learning curve on FSM-8, another attempt was made on FSM-9. The implementation plan for FSM-9 was the same as for FSM-8 except that the gages were also put onto the aft field joint. The FSM-9 field joints were typical in configuration (no intentional gas intrusions).

It appears that patience, perseverance and good fortune all paid off with the data obtained in FSM-9. All of the electrical displacement gages were 3-wire potentiometers. Eleven of these 12 electrical displacement gages gave great data (see Figures 16 through 21). Since there is a difference between the motion at the top and bottom of the motor, the data is separated in the figures for easier comparison. (FSM-10 data (discussed later) is also shown on these figures.)

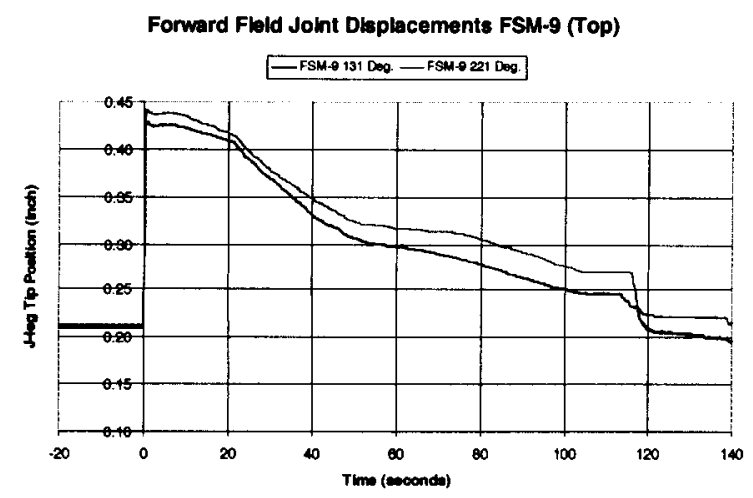

Figure 16. FSM-9 Forward Field Joint Electrical Displacement Gage Data (Top Side)

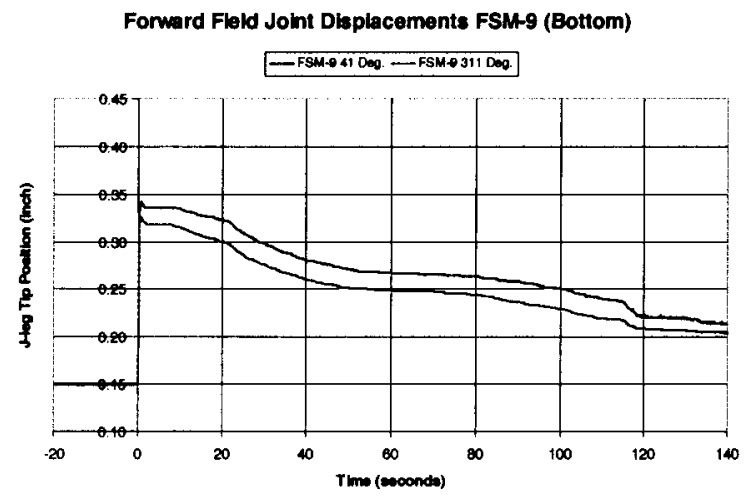

Figure 17. FSM-9 Forward Field Joint Electrical Displacement Gage Data (Bottom Side)

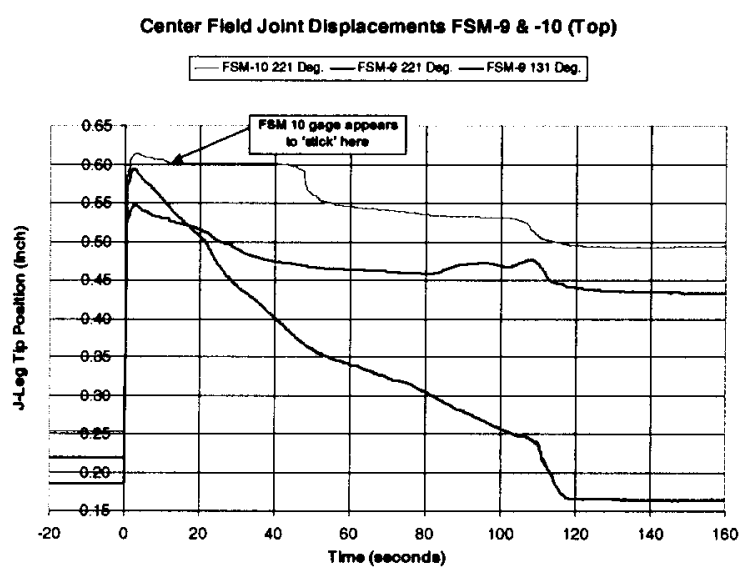

Figure 18. FSM-9 and -10 Center Field Joint Electrical Displacement Gage Data (Top Side)

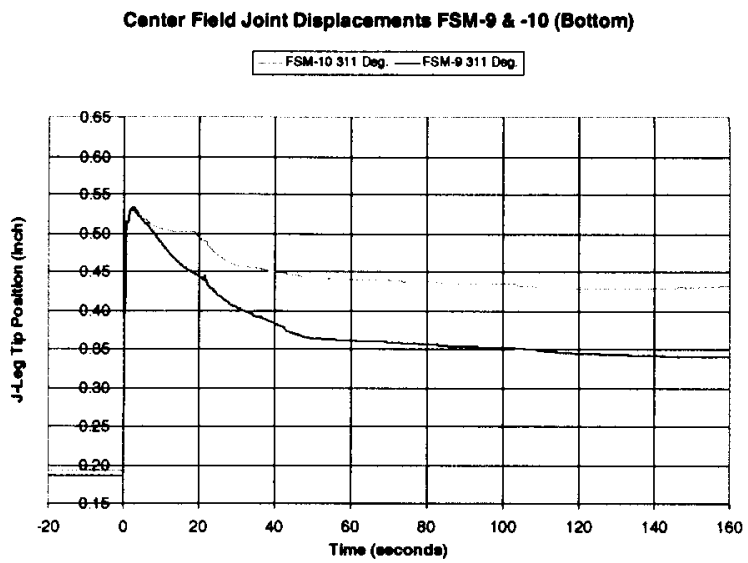

Figure 19. FSM-9 and -10 Center Field Joint Electrical Displacement Gage Data (Bottom Side) 


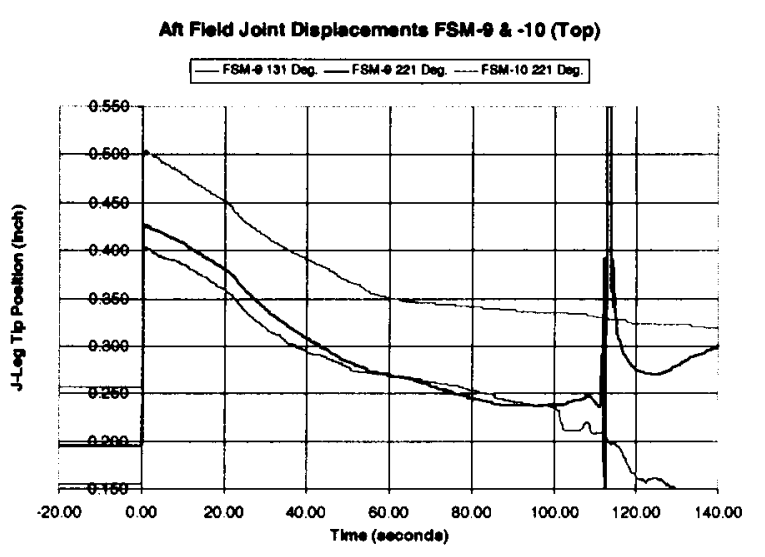

Figure 20. FSM-9 and -10 Aft Field Joint Electrical Displacement Gage Data (Top Side)

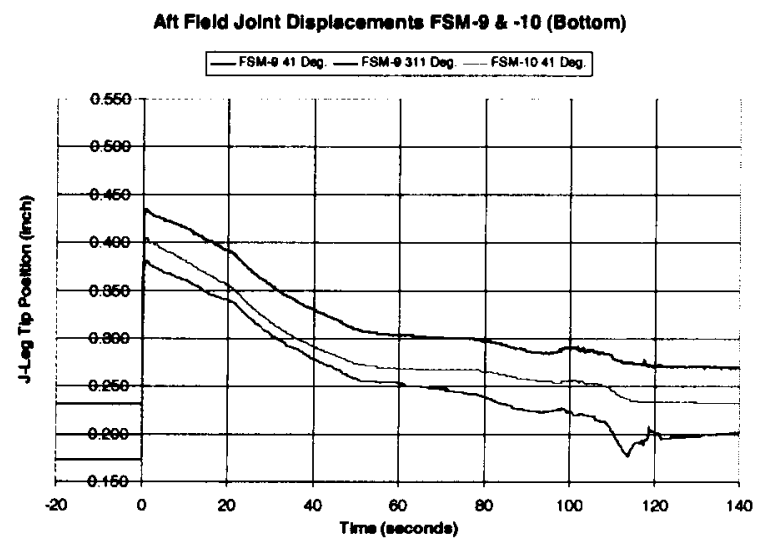

Figure 21. FSM-9 and -10 Aft Field Joint Electrical Displacement Gage Data (Bottom Side)

There was one undesirable condition with the FSM-9 displacement gages. Six of the 8 displacement gages on the aft joint experienced some heating and melting from the side adjacent to the propellant as the insulation burned back. In general, there were more heat effects toward the back of the gage (forward of the joint) and less at the front of the gage (at the joint pressurization slot). This was the first time displacement gages were used on the more severe aft field joint. All of the displacement gages remained in place. Data was lost from only one mechanical displacement gage. Based on the data, the electrical displacement gages produced reasonable data until at least 100 seconds into motor operation. This duration of gage functionality was much longer than was originally expected.

The electrical displacement gages show an increasing range of measured displacement as the motor burn progresses. The center and aft field joints appear to be worse than the forward joint. Part of this may be the result of the environment that the gage experiences over time.

The mechanical displacement gage results on FSM-9 were much better than on FSM-8. The maximum motion was generally in line with those of the electrical displacement gages. There was more variation in the mechanical displacement gage maximums than those of the electrical displacement gages.

There were a number of key findings from looking at all of the FSM-9 displacement gage data. There was a definite top-to-bottom (top half of the motor compared to the bottom half of the motor in a horizontal motor test orientation) maximum displacement trend observed in both gage types for all three joints. Both gages showed the maximum displacement greatest in the center field joint and least in the forward field joint. There were some differences in maximum displacement magnitudes between the mechanical and electrical displacement gages. Both gage types showed a little less motion in the aft field joint than predicted (closer to the forward field joint than predicted). Each field joint showed unique time dependent displacement characteristics (time of maximum and shape of displacement over time). The forward, center and aft field joints reach their maximum displacement at roughly $0.6,2.5$ and 0.8 seconds into motor operation, respectively. Since the RSRM motor is fully pressurized at 0.6 seconds, it appears that propellant relaxation characteristics play a more significant role in the center field joint.

\section{FSM-10}

The only configuration change between FSM-9 and FSM-10 was a precautionary change to shift the aft field joint gages radially outward by 0.20 ". This was a result of the heating and melting of displacement gages on the FSM-9 aft joint (previously discussed). This further reduced the potential that a gage may become a debris concern in the motor. With this shift, a new geometric correction factor was required for the aft joint gages.

Even though FSM-9 produced great data, FSM-10 was not as successful. Electrical lead wires again became a detriment. Functioning electrical displacement gages included, 0 of 4 on the forward joint, 2 of 4 on the center joint, and 2 of 4 on the aft joint. This FSM-10 data was included on Figures 18 through 21 for easier comparisons between FSM-9 and -10 . The most valuable part of the FSM-10 data is that it is so similar to FSM-9. This gives increased confidence that the behaviors that were measured are consistent and repeatable. 
The FSM-10 mechanical displacement gages performed similar to those of FSM-9. The forward and aft gages were the most consistent with the electrical displacement gages. Two of the center field joints were uncharacteristically low. Overall, the mechanical displacement gages are not as dependable as the electrical displacement gages.

\section{FUTURE MOTOR IMPLEMENTATION}

\section{FUTURE RSRM MOTORS}

Electrical displacement gages are planned for the next RSRM static test motor (FSM-11). The goal is to obtain reliable data for at least three full-scale static motors. Mechanical gages are not planned for future implementation.

\section{FIVE-SEGMENT RSRM DERIVATIVE (ETM-3)}

Electrical displacement gages are being installed on a five-segment RSRM derivative motor designated ETM-3 (Engineering Test Motor \#3). Although the J-joint design is the same, the additional segment and other factors are expected to make the motions somewhat different. Some of the environments in the aft portion of the motor are expected to be more severe than in the baseline RSRM motor. Having these gages on ETM-3 will provide displacement data to better characterize the differences in $\mathrm{J}$-joint behaviors.

\section{SUMMARY}

The field joint displacement gages have been extremely beneficial in understanding $\mathrm{J}$-joint motion during motor operation. The relative field joint motion magnitude differences for the individual joints have been measured. The time dependent nature of the individual field joints has provided more insight into the joint behaviors than was originally expected. The electrical displacement gages produced the best data. However, the electrical wire system to record the data outside the motor case is still a challenge. The mechanical displacement gage was a backup for, and did pave the way for the electrical displacement gage. Lessons and insights learned in the displacement gage and installation process development efforts have already benefited subsequent RSRM instrumentation efforts. The RSRM field joint motion data will provide an essential baseline for comparisons to a five-segment RSRM derivative motor (ETM-3).

\section{ACKNOWLEDGEMENTS}

There have been many involved with the development and implementation of these gages from many organizations. The writers thank all of the individuals who have contributed. The writers would like to acknowledge the RSRM Insulation Work Center and the Test Area Transducer Development Lab for their collective efforts. Some key individuals who helped to get this effort going include: John Shipley, Alan Godfrey, Rex Davis, Lloyd T. Johnson and Bruce McWhorter.

\section{REFERENCES}

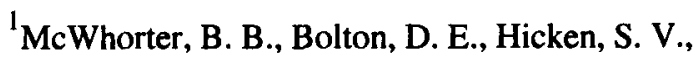
Allred, L. D., Cook, D. J., "Investigation Leads To Improved Understanding Of Space Shuttle RSRM Internal Insulation Joints", AIAA paper 2003-5108, July 2003.

${ }^{2}$ McWhorter, B. B. and Ewing M. E., "Real-Time Inhibitor Recession Measurements in the Space Shuttle Reusable Solid Rocket Motors", AIAA paper 20013280 , July 2001. 